\title{
Modulating the Functional Contributions of c-Myc to the Human Endothelial Cell Cyclic Strain Response
}

\author{
Nicole E. Hurley ${ }^{a}$ Lisa A. Schildmeyer ${ }^{b}$ Kami A. Bosworth ${ }^{b}$ Yumiko Sakurai $^{b}$ \\ Suzanne G. Eskin ${ }^{b}$ Laurence H. Hurley ${ }^{c}$ Larry V. Mclntire ${ }^{a, b}$ \\ a Bioengineering Program, Georgia Institute of Technology, and ${ }^{\mathrm{b} C o u l t e r ~ D e p a r t m e n t ~ o f ~ B i o m e d i c a l ~ E n g i n e e r i n g, ~}$ \\ Georgia Institute of Technology and Emory University School of Medicine, Atlanta, Ga., and ' College of Pharmacy, \\ University of Arizona, Tucson, Ariz., USA
}

\section{Key Words}

Cyclic strain $\cdot$ c-Myc $\cdot$ Endothelial cells $\cdot$ Vascular

endothelial growth factor

\begin{abstract}
This study addresses whether pathological levels of cyclic strain activate the c-Myc promoter, leading to c-Myc transcription and downstream gene induction in human umbilical vein endothelial cells (HUVEC) or human aortic endothelial cells (HAEC). mRNA and protein expression of c-Myc under physiological (6-10\%) and pathological cyclic strain conditions (20\%) were studied. Both c-Myc mRNA and protein expression increased 2-3-fold in HUVEC cyclically strained at $20 \%$. c-Myc protein increased 4-fold in HAEC. In HUVEC, expression of mRNA peaked at 1.5-2 h. Subsequent$l y$, the effect of modulating c-Myc on potential downstream gene targets was determined. A small molecular weight compound that binds to and stabilizes the silencer element in the c-Myc promoter attenuates cyclic strain-induced cMyc transcription by about $50 \%$. This compound also modulates c-Myc downstream gene targets that may be instrumental in induction of vascular disease. Cyclic strain-induced gene expression of vascular endothelial growth factor, pro-
\end{abstract}

\section{KARGER}

Fax +41613061234 E-Mail karger@karger.ch www.karger.com
(C) 2009 S. Karger AG, Basel www.karger.com/jvr liferating cell nuclear antigen and heat shock protein 60 are attenuated by this compound. These results offer a possible mechanism and promising clinical treatment for vascular diseases initiated by increased cyclic strain.

Copyright $\odot 2009$ S. Karger AG, Basel

\section{Introduction}

Numerous studies have attempted to characterize the onset and progression of cardiovascular disease. With an increased biological understanding of the cell cycle events involved in vascular pathogenesis, it would be possible to better treat and/or prevent these diseases. Although numerous genes have identified roles in atherosclerosis, the mechanism of their induction is largely uncharacterized. Cyclic strain, which results from pulsatile blood flow, is a major modulator in localization of vascular diseases $[1,2]$. Under normal physiological conditions, the human aorta undergoes $8-10 \%$ oscillations in external diameter [3]. Thus, normal physiological cyclic strain can be modeled as about $10 \%[4,5]$. When certain pathological conditions arise in vivo, such as hypertension, atherosclerotic plaque development or intimal

Dr. Larry V. McIntire

Department of Biomedical Engineering, Georgia Institute of Technology

313 Ferst Drive, Suite 2116

Atlanta, GA 30332-0535 (USA)

Tel. +1 404894 5057, Fax +1 404385 5028, E-Mail larry.mcintire@bme.gatech.edu 
thickening necessitating intracoronary stenting, cyclic strain is elevated as a result of increased pulse pressure due to increased stiffness of the arterial wall. This induces localized vessel remodeling, and is accompanied by an atherogenic endothelium $[3,6]$. Pathological strain is modeled in vitro as about $20 \%$ [6-10]. By implementing a cyclic strain model, it is possible to mimic certain hemodynamic conditions associated with the development of atherosclerosis and thereby study it from a mechanistic point of view.

To study transcriptional changes occurring in vasculoproliferative disease, we investigated potential parallels in cancer research. The oncogene c-Myc is known to be involved in the modification of cell cycle-related events (proliferation, differentiation and apoptosis), and emerging cancer therapies target inhibition of c-Myc expression [11]. For treatment of cardiovascular diseases, attempts have been made to downregulate c-Myc by using antioxidants, RNA synthesis inhibitors or antisense oligonucleotides [12].

The approach in the present study differs in using a small molecule inhibitor against the c-Myc promoter. c-Myc transcription takes place when transcriptional factors, such as Sp1, heterogeneous nuclear ribonucleoprotein $\mathrm{K}$ (hnRNP K) and cellular nucleic acid-binding protein (CNBP), bind to the nuclease hypersensitivity element $\left(\mathrm{NHE} \mathrm{III}_{1}\right)$ in the c-Myc promoter. A highthroughput assay was used to identify compounds able to repress c-Myc gene expression by binding to the silencer element of the c-Myc promoter, thereby preventing the binding of hnRNP K and CNBP to the c-Myc promoter $[13,14]$.

This study examines the functional contributions of c-Myc to the EC cyclic strain response. Our findings indicate that pathogenic levels of cyclic strain (20\%) activate the c-Myc promoter, causing a 2.5 -fold increase in c-Myc mRNA and a 2-fold increase in c-Myc protein expression in human umbilical vein endothelial cells (HUVEC) as well as a 4-fold upregulation in c-Myc protein in human aortic endothelial cells (HAEC). In HUVEC, this upregulation peaked at $1.5-2 \mathrm{~h}$ and returned to basal levels by $3 \mathrm{~h}$. The compound targeting the silencer element of the c-Myc promoter attenuated cyclic strain-induced c-Myc transcription by about $50 \%$. This inhibitor also decreased cyclic strain-induced gene and protein expression of vascular endothelial growth factor (VEGF), proliferating cell nuclear antigen (PCNA) and heat shock protein 60 (HSP60), all downstream genes regulated by c-Myc and related to cardiovascular disease.

Modulating Cyclic Strain-Induced c-Myc Expression

\section{Materials and Methods}

\section{Materials}

CytoTox-ONE ${ }^{\mathrm{TM}}$ Homogeneous Membrane Integrity Assay (necrosis), Apo-ONE ${ }^{\circledR}$ Homogeneous Caspase-3/7 Assay (apoptosis) and CellTiter 96 Nonradioactive Cell Proliferation Assay were purchased from Promega.

\section{Cell Culture}

Pooled HUVEC (Cambrex) were grown to confluence in complete media (Media-199; Cellgro), 20\% fetal bovine serum (Cellgro), $25 \mathrm{mg} / \mathrm{ml}$ purified endothelial mitogen (Biomedical Technologies), $2 \mathrm{mM} \mathrm{L}$-glutamine (Cellgro), $2.5 \mathrm{U} / \mathrm{ml}$ heparin sodium (American Pharmaceutical Partners), $50 \mathrm{U} / \mathrm{ml}$ penicillin (Cellgro) and $50 \mu \mathrm{g} / \mathrm{ml}$ streptomycin (Cellgro), and maintained at $37^{\circ} \mathrm{C}$ in the presence of humidified $5 \% \mathrm{CO}_{2} / 95 \%$ air. HUVEC were used in experiments at passage 4-5. Pooled HAEC (Lonza) were grown to confluence in EGM-2 medium (Clonetics), and were used at passage 5 in experiments.

Cell suspensions $\left(1 \times 10^{6}\right.$ cells in $1 \mathrm{ml}$ of media) were seeded onto $4 \times 4 \mathrm{~cm}$ silicone membranes (Specialty Manufacturing) precoated with $1 \%$ gelatin and crosslinked with $0.5 \%$ glutaraldehyde [15]. Twelve hours prior to cyclic strain, complete media were replaced with quiescent media, which have $5 \%$ serum and do not contain endothelial growth factor or heparin.

Cyclic Strain Experiments

Cells were subjected to cyclic strain $(1 \mathrm{~Hz}, 10$ or $20 \%$ strain $)$ as previously described [16]. This model incorporated a motion control, which simulates the fluid agitation (low level reversing shear stress) of the cyclic strain condition to which the cells might respond $[16,17]$. An additional control utilized cells cultured on membranes maintained under static incubation without any fluid motion. Immediately after stretch and, if applicable, drug exposure, membranes were removed from the cyclic strain chambers and washed with ice-cold $1 \times$ PBS. Cells were detached with a sterile cell scraper and collected in fresh $1 \times$ PBS for RNA and protein analysis

\section{Compound 0012}

The structure of compound 0012, which targets the c-Myc promoter, was authenticated through nuclear magnetic resonance and liquid chromatography mass spectrometry. This synthetic aromatic compound prevents transcription of c-Myc by stabilizing the $\mathrm{NHE} \mathrm{III}_{1}$ in the $\mathrm{c}-\mathrm{Myc}$ promoter. This region controls up to $90 \%$ of the transcriptional activity of this gene occurring at the predominant c-Myc promoters [18]. The NHE $\mathrm{III}_{1}$ sequence includes an inordinate number of guanine residues on one strand and the corresponding cytosine residues on the opposing strand. The unique G-rich and C-rich sequences impart a special property to DNA in this region - the ability of NHE III $_{1}$ to convert to a single-stranded region in which the purine-rich strand adopts a G-quadruplex structure $[19,20]$. This G-quadruplex structure has been shown to be the silencer element $[11,14]$. As a consequence of compound 0012 binding to and stabilizing this silenced form, the binding proteins of transcriptional factors hnRNP K and CNBP, which directly mediate transcriptional activation, can be prevented from binding. In other words, by transforming the purine-rich sequence of the NHE $\mathrm{III}_{1}$ to a parallel G-quadruplex structure, hnRNP K and CNBP cannot bind. The compound 0012 
binds to the parallel G-quadruplex structure and thereby silences c-Myc gene expression [11].

\section{Preparation of Compound 0012}

Lyophilized compound 0012 was resuspended in $100 \%$ sterile DMSO at $10 \mathrm{mM}$ and frozen at $-20^{\circ} \mathrm{C}$. At the onset of cyclic strain, the compound was diluted in quiescent media to a final concentration of $5 \mu \mathrm{M}$.

\section{Quantitative RT-PCR}

RNA was extracted using the RNeasy MinElute Cleanup Kit (Qiagen). For quantitative RT-PCR, $0.1 \mu \mathrm{g}$ of total RNA was reverse transcribed into cDNA with SuperScript II (Invitrogen). Quantitative RT-PCR was performed according to the following protocol: each $16 \mu$ l reaction contained $1 \times$ iQ Sybr Green Supermix (Bio-Rad), $0.3 \mu \mathrm{M}$ of forward and reverse primers (table 1), and 1:2 dilution of cDNA. Reactions were carried out in a MyiQ Single-Color Real-Time PCR Detection System (Bio-Rad). Amplification conditions were: $T_{\mathrm{m}}(50 \mathrm{sec}), 95^{\circ} \mathrm{C}(60 \mathrm{sec}) ; 40$ repetitions.

\section{Protein Isolation and Western Blot Analysis}

Pelleted cells were resuspended and homogenized by syringe needle in $150 \mu \mathrm{l}$ cell lysis buffer [50 mM Tris- $\mathrm{HCl}(\mathrm{pH} 7.4), 150$ $\mathrm{mM} \mathrm{NaCl}, 1 \%$ Triton X-100, 2 mM EDTA]. Protein content was determined by Bradford assay (Bio-Rad) using cell lysis buffer as the standard. Equal concentrations of protein were resolved by SDS-PAGE on 7.5\% Tris-HCl-precast polyacrylamide gels (Bio$\mathrm{Rad})$. Proteins were electroblotted onto nitrocellulose. Blots were incubated for $1 \mathrm{~h}$ at room temperature with $3 \%$ nonfat dried milk to block nonspecific binding. Proteins were detected by incubation with primary antibodies [rabbit anti-(c-Myc) monoclonal (Cell Signaling); mouse anti-(VEGF) polyclonal (Santa Cruz Biotechnology); goat anti-(HSP60) polyclonal (Assay Designs); or rabbit anti-(PCNA) polyclonal (Santa Cruz Biotechnology); $1: 1,000$ ] overnight at $4^{\circ} \mathrm{C}$. Blots were incubated with secondary antibodies [horseradish peroxidase-conjugated polyclonal anti(rabbit IgG), anti-(mouse IgG), or anti-(goat IgG); 1:10,000] for $1 \mathrm{~h}$ at room temperature. Protein was detected with an enhanced chemiluminescence detection system (Amersham Biosciences). Equal protein loading was verified by mouse-anti-( $\beta$-actin) monoclonal antibody (Sigma-Aldrich). Western blots were quantified using densitometry (Kodak EDAS 1D Imaging System).

Data Analysis

Statistical comparisons were evaluated with Student's t test. Data are given as mean \pm SEM. Significance was defined as $\mathrm{p}$ value $<0.05$ or $<0.01$.

\section{Results}

Cyclic Strain Transiently Increases c-Myc $m R N A$ and Protein Expression

Upon exposure of HUVEC to $20 \%$ cyclic strain, c-Myc mRNA increased to a maximum at $1-2 \mathrm{~h}(1 \mathrm{~h}: 2.6 \pm 0.5-$ fold increase vs. static; 2 h: $2.5 \pm 0.4$-fold increase vs. static), and returned to baseline after $3 \mathrm{~h}$ (fig. 1a). In con-
Table 1. Primer sets for $\mathrm{qRT}-\mathrm{PCR}$

\begin{tabular}{lll}
\hline Gene & Primer sequence & $\mathrm{T}_{\mathrm{m}},{ }^{\circ} \mathrm{C}$ \\
\hline c-MYC & 5'-GCTGCTTAGACGCTGGATT-3' $^{\prime}$ & 65 \\
& 5'-TCCTCCTCGTCGCAGTAGA-3' & \\
\hline ACTIN & 5'-CTGGAACGGTGAAGGTGACA-3' & 65 \\
& 5'-AAGGGACTTCCTGTAACAACGCA-3' & \\
\hline HSP60 & 5'-AGTCAAGGCTCCAGGGTTTGG-3' & 65 \\
& 5'-TGGCATCGTCTTTGGTCACA-3' & \\
\hline PCNA & 5'-CCTGACAAATGCTTGCTGACC-3' & 63.1 \\
& $5^{\prime}$-CTTGAGGATGGAGCCCTGGA-3' & \\
\hline VEGF & 5'-TTTGCTTGCCATTCCCCACT-3' & 61.2 \\
& 5'-GGTCACTCACTTTGCCCCTGT-3' & \\
\hline
\end{tabular}

trast, c-Myc mRNA was not significantly affected in cells subjected to motion control. In HUVEC, Western blots demonstrated that c-Myc protein peaked at $1-2 \mathrm{~h}(1 \mathrm{~h}: 1.8$ \pm 0.1 -fold increase vs. static; $2 \mathrm{~h}: 1.9 \pm 0.6$-fold increase vs. static) and returned to basal levels by $4 \mathrm{~h}$. In HAEC, c-Myc protein increased $4.2 \pm 0.7$-fold versus static after $2 \mathrm{~h}$ of cyclic strain (fig. 1b).

\section{c-Myc mRNA Is Induced by Pathogenic Levels of Cyclic Strain}

The threshold magnitude of strain necessary to induce c-Myc mRNA in cultured HUVEC was determined by exposing cells to $5,10,15$ or $20 \%$ cyclic strain for $1.75 \mathrm{~h}$ at $1 \mathrm{~Hz}$ (fig. 1c). Induction of c-Myc mRNA was significant upon exposure to higher levels of cyclic strain (15\%: $2.0 \pm 0.4$-fold increase vs. static; $20 \%: 3.2 \pm 0.5$-fold increase vs. static). The c-Myc mRNA expression at $20 \%$ cyclic strain is over 2 -fold higher than that at $10 \%$.

\section{Compound 0012 Is Not Cytotoxic}

To study whether cyclic strain-induced c-Myc transcription can be attenuated, the strain protocol was repeated in the presence of a compound targeted to the cMyc promoter. Compound 0012, developed by the University of Arizona, stabilizes the silencer element of the c-Myc promoter by stabilizing the $\mathrm{NHE} \mathrm{III}_{1}$ region.

Incubation with compound 0012 produced no changes in cell morphology or detachment of cells. The $\mathrm{LD}_{50}$, the concentration of drug at which $50 \%$ of HUVEC die, was determined to be greater than $100 \mu \mathrm{M}$. For the concentration utilized $(5 \mu \mathrm{M})$, extrapolation of the data predicts an $84 \%$ cell survival rate compared with untreated HUVEC. Cell injury was evaluated by measuring cellular 


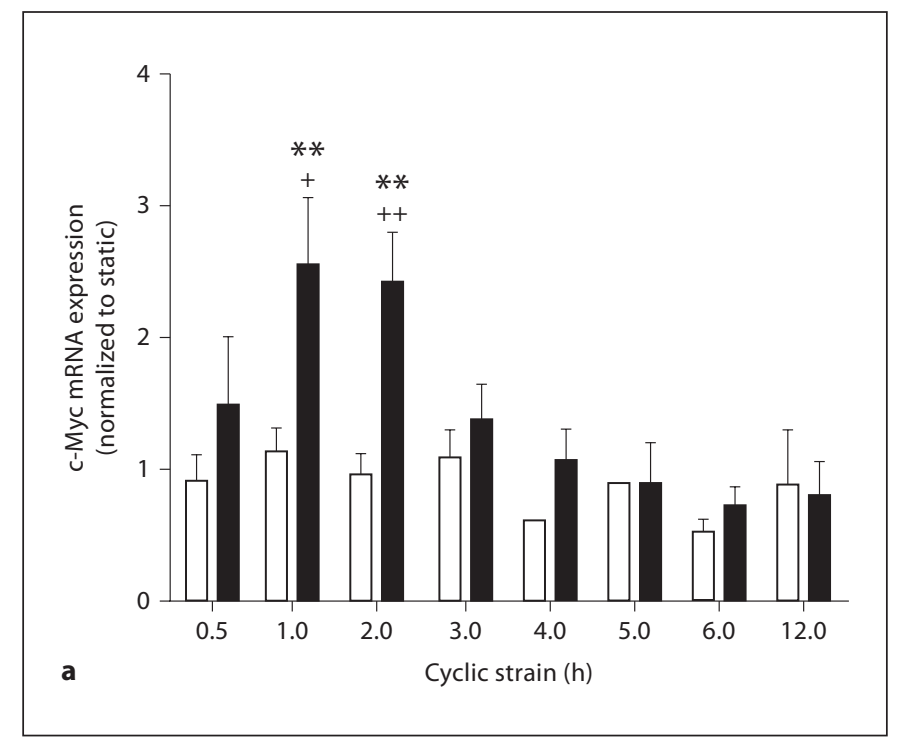

Fig. 1. Effect of duration and magnitude of cyclic strain on endothelial cell c-Myc mRNA and protein expression. a HUVEC cMyc mRNA is transiently induced by $20 \%$ cyclic strain. Expression is normalized to static conditions (4-15 independent experiments). Error bars represent mean \pm SEM. White bars $=$ Motion control; black bars $=$ cyclic strain. ${ }^{* *} \mathrm{p}<0.01$ vs. static control; ${ }^{+} \mathrm{p}<0.05$ vs. motion control; ${ }^{++} \mathrm{p}<0.01$ vs. motion control. b HUVEC time course of c-Myc protein expression showed c-Myc protein maximum (1.9-fold) increase after $2 \mathrm{~h}$ of $20 \%$ cyclic strain (black bars, 6 independent experiments). In HAEC after 2 h $20 \%$ cyclic strain (hatched bars, 4 independent experiments), c-Myc increased 4.2-fold. Error bars represent mean \pm SEM. Representative immunoblots of $\mathrm{c}$-Myc and $\beta$-actin. ${ }^{*} \mathrm{p}<0.05$ vs. static control. c c-Myc mRNA is induced by pathogenic levels of cyclic strain. HUVEC were exposed to cyclic strain $(1 \mathrm{~Hz})$ of the indicated magnitude for $1.75 \mathrm{~h}$. Total mRNA expression from 4-9 independent experiments was normalized versus $\beta$-actin expression. Error bars represent mean \pm SEM. White bars $=$ Motion control; black bars $=$ cyclic strain. ${ }^{*} \mathrm{p}<0.05$ vs. static control; ${ }^{* *} \mathrm{p}<0.01$ vs. static control; ${ }^{++} \mathrm{p}<0.01$ vs. motion control.

caspase-3/7 activity and lactate dehydrogenase activity in cell culture media. Caspase-3/7 and LDH activity from cells subjected to cyclic strain and compound 0012 for 1-3 h were not significantly different from untreated cyclically-strained control cells (data not shown).

\section{c-Myc Transcriptional Activation Can Be Modulated by Compound 0012}

At maximum c-Myc expression, compound 0012 prevented the upregulation of $\mathrm{c}-\mathrm{Myc} \mathrm{mRNA}$ expression during exposure of HUVEC to cyclic strain (1 h: $33 \%$ decrease vs. untreated HUVEC; 2 h: $28 \%$ decrease vs. untreated
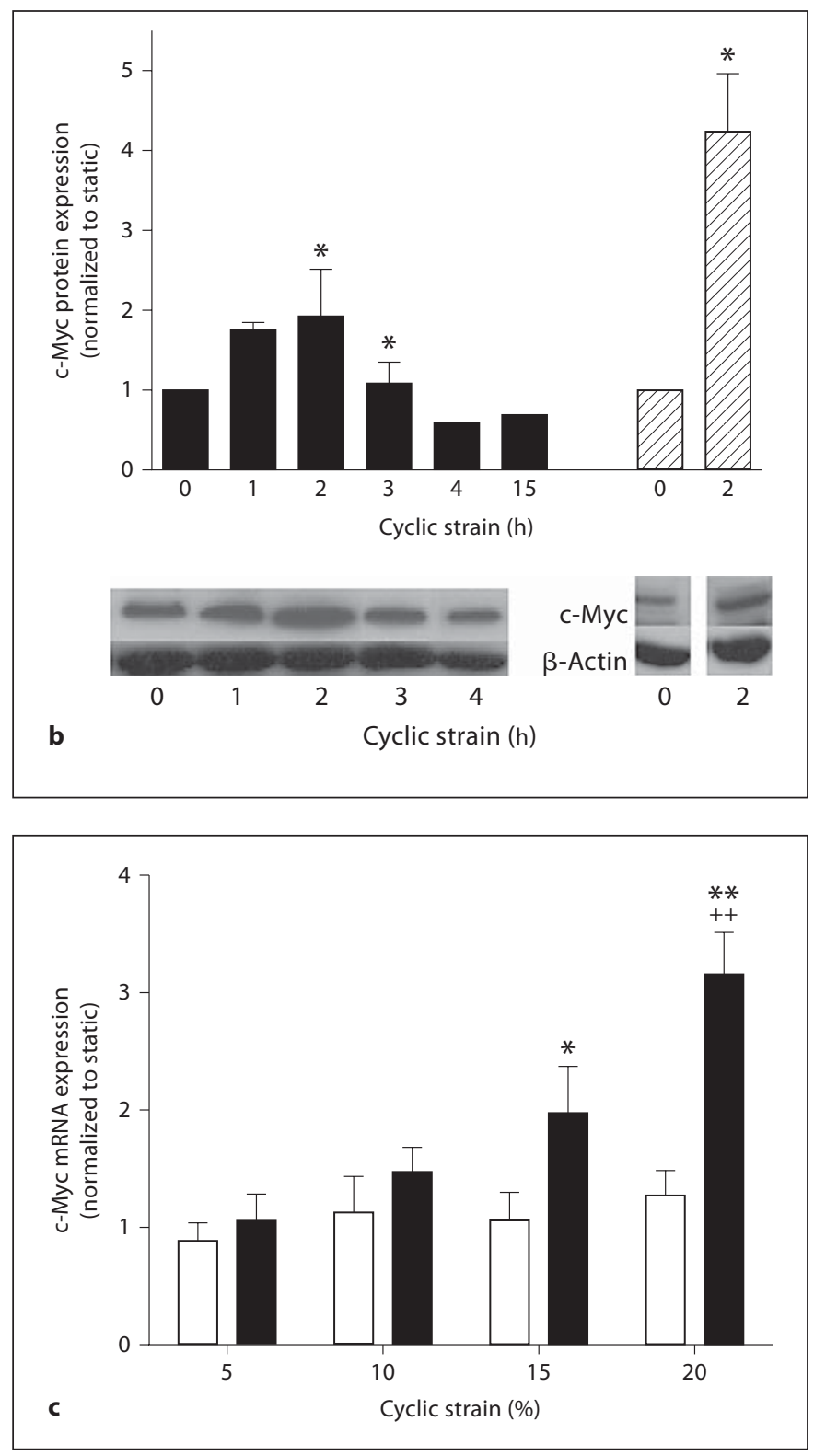

HUVEC; fig. 2a). Western blots demonstrated that cyclic strain-induced c-Myc expression can also be attenuated at the protein level ( $1 \mathrm{~h}$ : $55 \%$ decrease vs. untreated HUVEC; 2 h: 64\% decrease vs. untreated HUVEC). Thus, not only are c-Myc mRNA and protein expression induced by cyclic mechanical strain at least in part though the promoter region, this expression can be attenuated by stabilizing the c-Myc silencer element.

Downstream Target Genes of c-Myc

We next examined mRNA and protein expression of genes which may be directly regulated by c-Myc protein.

J Vasc Res 2010;47:80-90 
PCNA, HSP60 and VEGF have been identified as both regulated by $\mathrm{c}-\mathrm{Myc}$ and playing a significant role in the progression of cardiovascular disease.

\section{Cyclic Strain Transiently Increases PCNA mRNA and} Protein Expression

Exposure of HUVEC to varying time periods of cyclic strain $(1 \mathrm{~Hz}, 20 \%)$ resulted in transient increases in PCNA mRNA and protein expression (fig. 3). PCNA was reproducibly induced maximally by $20 \%$ cyclic strain at $2-5 \mathrm{~h}$. Induction of this gene was first detectable at $2 \mathrm{~h}(1.4 \pm$ 0.2 -fold vs. static), peaked at $3 \mathrm{~h}(1.75 \pm 0.36$-fold vs. static), and remained sustained at 4 and $5 \mathrm{~h}$ ( $4 \mathrm{~h}: 1.2 \pm$ 0.35 -fold vs. static; 5 h: $1.4 \pm 0.2$-fold vs. static) before returning to basal levels at $6 \mathrm{~h}(0.7 \pm 0.3$-fold vs. static). Cyclic strain also resulted in an increase in PCNA protein expression. Protein expression increased $1.5 \pm 0.2$ fold versus static at $2 \mathrm{~h}$ and $2.0 \pm 0.05$-fold versus static at $6 \mathrm{~h}$.

\section{Compound 0012 Attenuates PCNA Expression}

Compared with cyclically-strained untreated HUVEC, compound 0012 significantly attenuated PCNA expression at both the mRNA and protein levels. For mRNA expression (fig. 3a), this response was seen after $2-5$ h of cyclic strain (2 h: $46 \%$ decrease vs. untreated HUVEC; 3 h: 63\% decrease vs. untreated HUVEC; 4 h: $45 \%$ decrease vs. untreated HUVEC; 5 h: $43 \%$ decrease vs. untreated HUVEC). Western blots demonstrated that cyclic strain-induced PCNA expression can also be modulated at the protein level ( $2 \mathrm{~h}: 31 \%$ decrease vs. untreated HUVEC; 6 h: $32 \%$ decrease vs. untreated HUVEC; fig. 3b). Thus, by silencing c-Myc expression through the use of compound 0012, the cyclic strain-induced expression of PCNA mRNA and protein can be attenuated.

\section{Cyclic Strain Transiently Increases VEGF $m R N A$ and}

\section{Protein Expression}

Exposure of HUVEC to varying time periods of cyclic strain $(1 \mathrm{~Hz}, 20 \%)$ increased VEGF $m R N A$ and protein expression (fig. 4). Induction of VEGF was first detectable at $2 \mathrm{~h}(2.9 \pm 0.5$-fold vs. static), sustained at $3 \mathrm{~h}(2.1$ \pm 0.5 -fold vs. static), and peaked at 4 and $5 \mathrm{~h}$ ( $4 \mathrm{~h}: 3.5 \pm$ 1.0 -fold vs. static; 5 h: $3.3 \pm 0.9$-fold vs. static), before returning to basal levels at $6 \mathrm{~h}$ (1.2 \pm 0.3 -fold vs. static). Western blot analysis showed that cyclic strain increased VEGF protein expression maximally at $2 \mathrm{~h}(2.6 \pm 0.4-$ fold vs. static), then declined at $4 \mathrm{~h}(2.3 \pm 0.03$-fold vs. static) and $6 \mathrm{~h}(2.0 \pm 0.04$-fold vs. static).
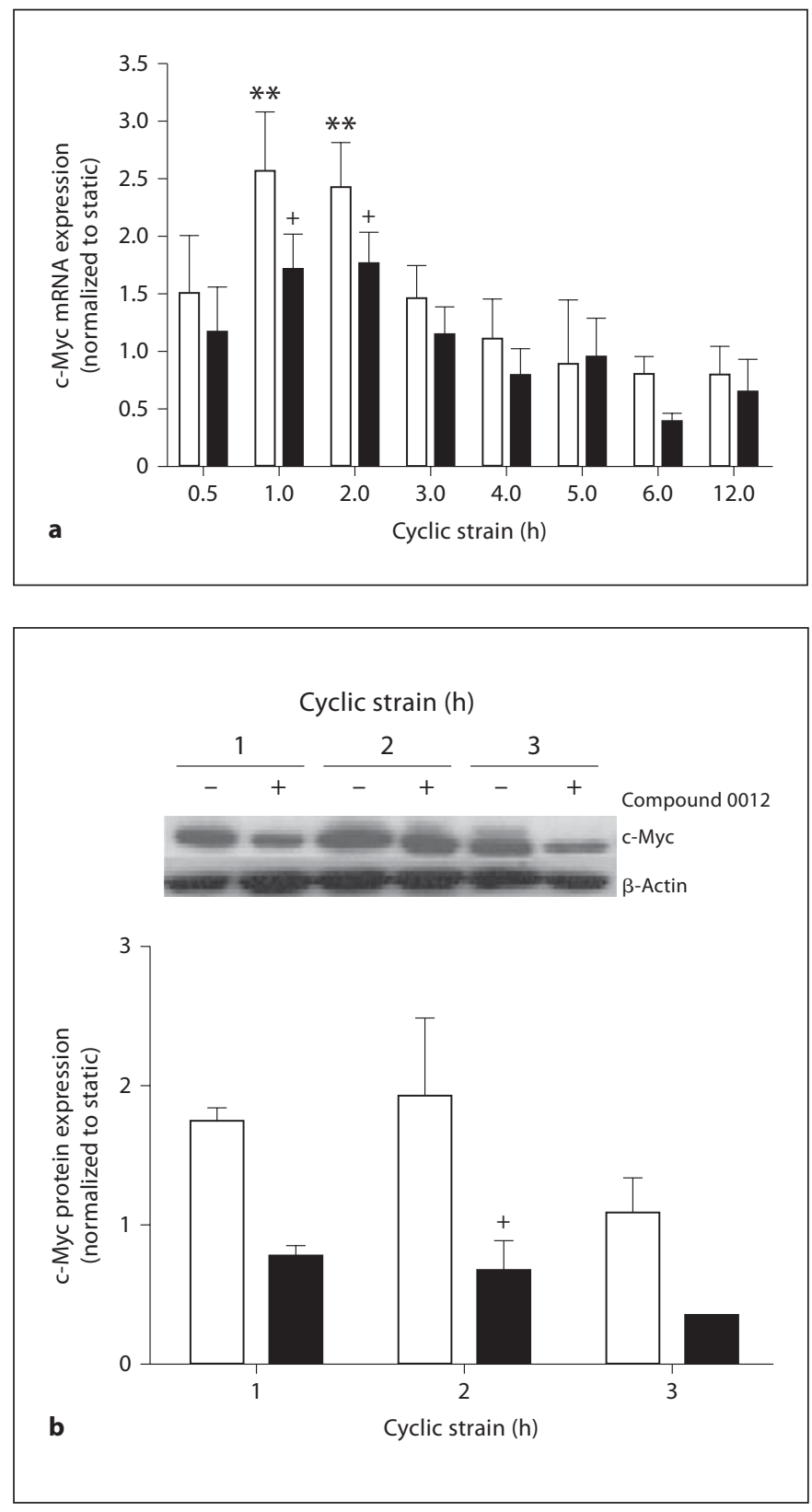

Fig. 2. Cyclic strain-induced c-Myc expression can be attenuated by use of compound 0012. HUVEC were exposed to cyclic strain $(1 \mathrm{~Hz}, 20 \%)$ for the indicated times in the presence (black bars) or absence (white bars) of compound 0012. Expression was normalized to expression in static HUVECs. Error bars represent mean \pm SEM. a mRNA expression from 4-15 independent experiments. ${ }^{+} \mathrm{p}<0.05$ vs. untreated cells; ${ }^{* *} \mathrm{p}<0.01$ vs. static control. b Representative immunoblot of c-Myc and $\beta$-actin. Protein expression from densitometry of 6 independent experiments. ${ }^{+} \mathrm{p}<$ 0.05 vs. untreated cells. 

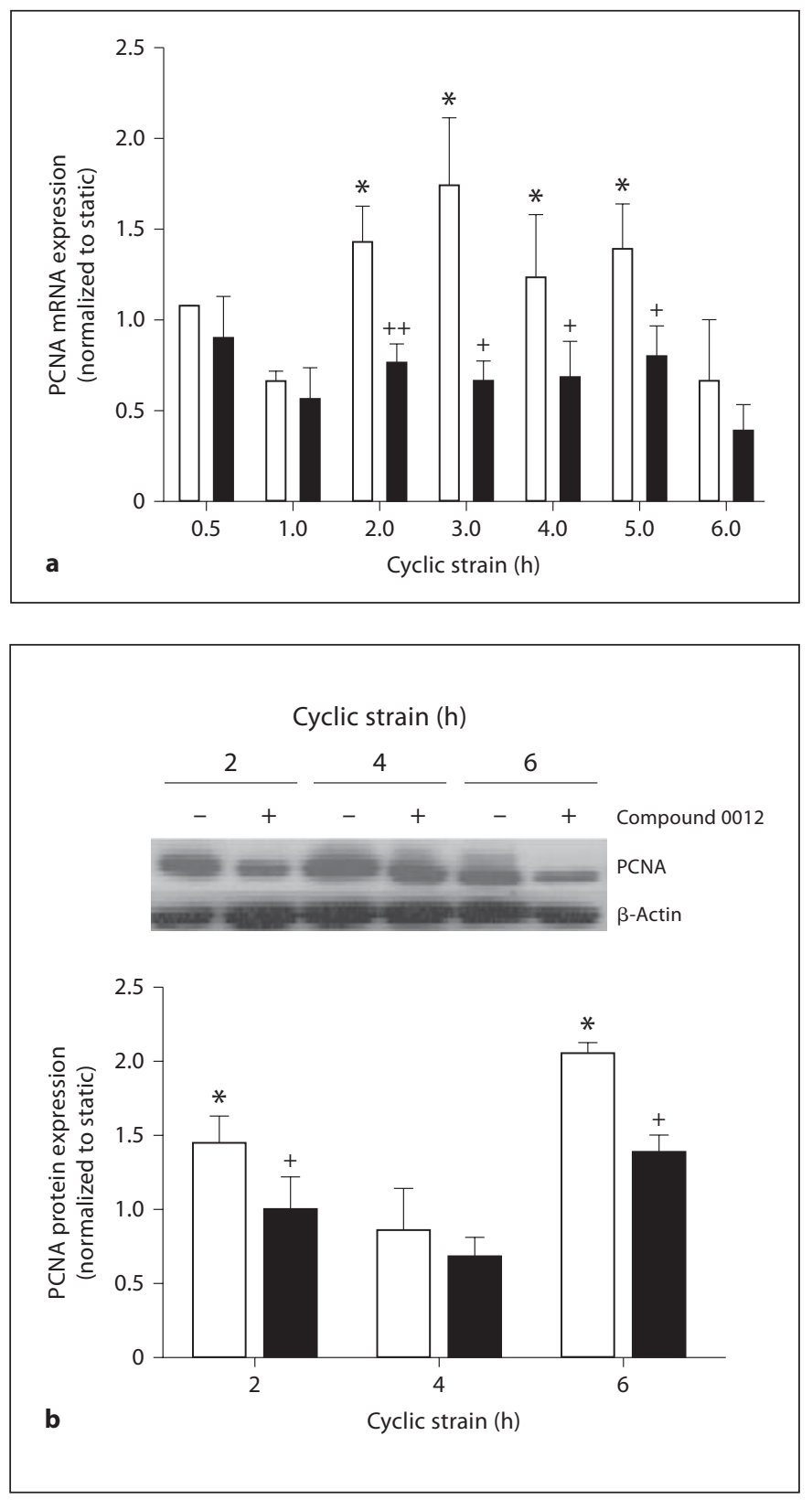

Fig. 3. Cyclic strain-induced PCNA expression can be attenuated by use of compound 0012. HUVEC were exposed to cyclic strain ( $1 \mathrm{~Hz}, 20 \%)$ for the indicated times in the presence (black bars) or absence (white bars) of compound 0012. Expression was normalized to expression in static HUVECs. Bars represent mean \pm SEM. a mRNA expression from 3-10 independent experiments. ${ }^{*} \mathrm{p}<0.05$ vs. static control; ${ }^{+} \mathrm{p}<0.05$ vs. untreated cells; ${ }^{++} \mathrm{p}<$ 0.01 vs. untreated cells. b Representative immunoblot of PCNA and $\beta$-actin. Protein expression from densitometry of 5 independent experiments. ${ }^{+} \mathrm{p}<0.05$ vs. untreated cells; ${ }^{*} \mathrm{p}<0.01$ vs. static control.
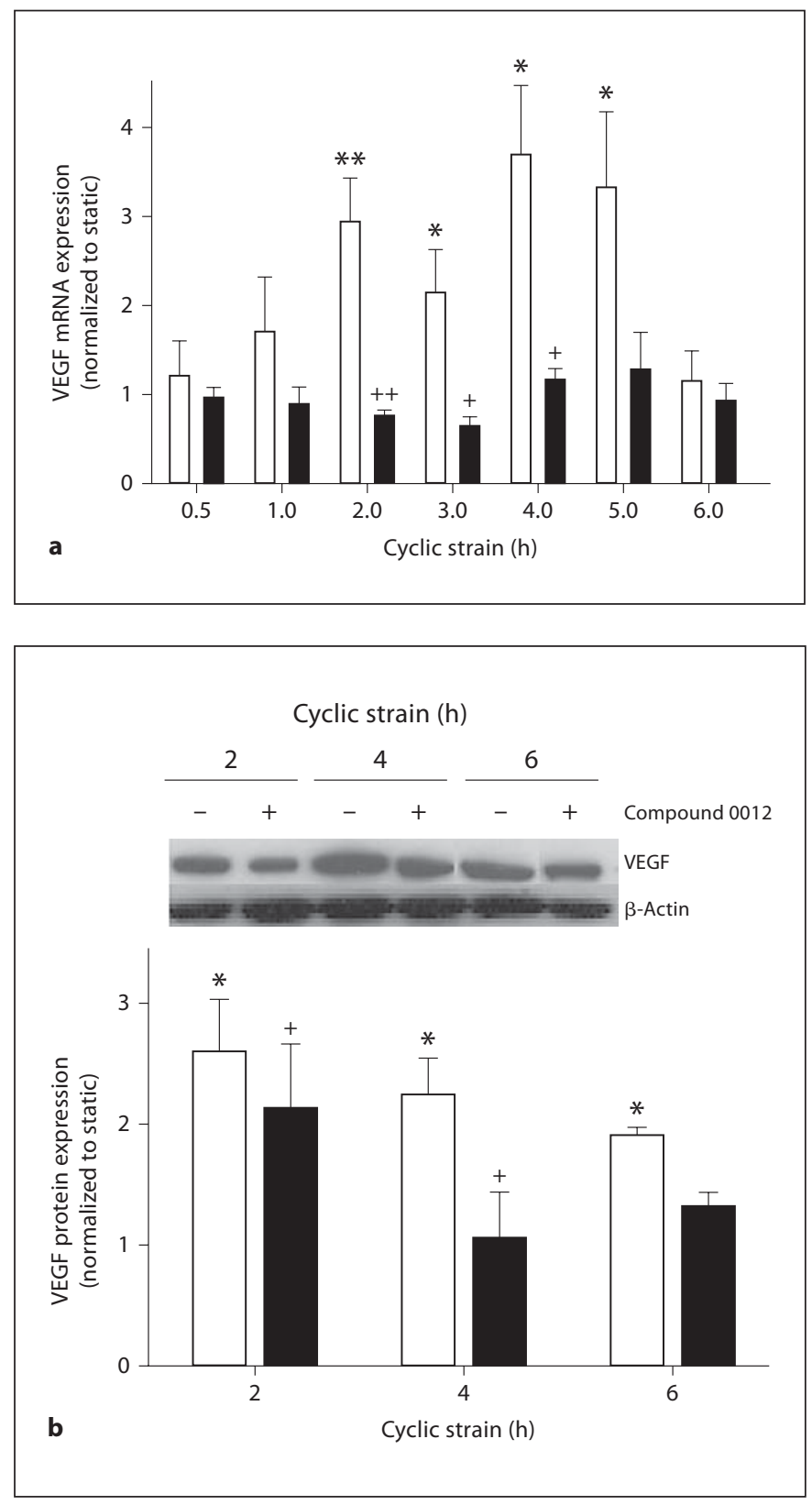

Fig. 4. Cyclic strain-induced VEGF expression can be attenuated by use of compound 0012. HUVEC were exposed to cyclic strain $(1 \mathrm{~Hz}, 20 \%)$ for the indicated times in the presence (black bars) or absence (white bars) of compound 0012. Expression was normalized to static HUVEC expression. Bars represent mean \pm SEM. a mRNA expression from 3-12 independent experiments. ${ }^{*} \mathrm{p}<$ 0.05 vs. static control; ${ }^{* *} \mathrm{p}<0.01$ vs. static control; ${ }^{+} \mathrm{p}<0.05$ vs. untreated cells; ${ }^{++} \mathrm{p}<0.01$ vs. untreated cells. b Representative immunoblot of VEGF and $\beta$-actin. Protein expression from densitometry of 5 independent experiments. ${ }^{*} \mathrm{p}<0.05$ vs. static control; ${ }^{+} \mathrm{p}<0.05$ vs. untreated cells. 

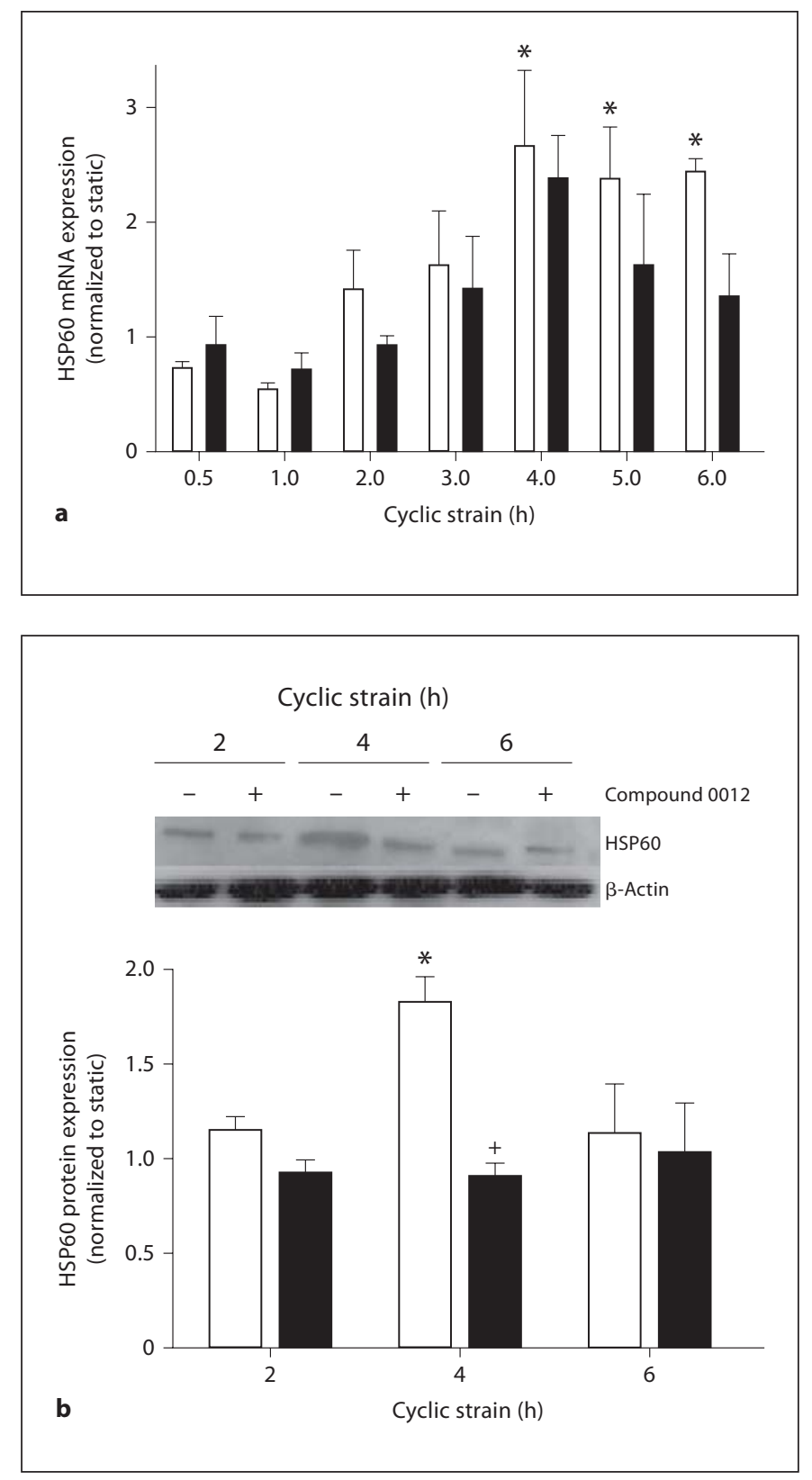

Fig. 5. Cyclic strain-induced HSP60 expression can be attenuated by use of compound 0012. HUVEC were exposed to cyclic strain $(1 \mathrm{~Hz}, 20 \%)$ for the indicated times in the presence (black bars) or absence (white bars) of compound 0012. Expression was normalized to expression in static HUVECs. Bars represent mean \pm SEM. a mRNA expression from 3-9 independent experiments. ${ }^{*} \mathrm{p}<0.05$ vs. static control. b Representative immunoblot of HSP60 and $\beta$-actin. Protein expression from densitometry of 4 independent experiments. ${ }^{*} \mathrm{p}<0.05$ vs. static control; ${ }^{+} \mathrm{p}<0.05$ vs. untreated cells.

\section{Compound 0012 Attenuates VEGF Expression}

Compared with untreated HUVEC under cyclic strain, compound 0012 significantly attenuated VEGF expression at both the mRNA and protein levels. For mRNA expression, this response was seen from $2-5 \mathrm{~h}$ of cyclic strain ( 2 h: $74 \%$ decrease vs. untreated HUVEC; 3 h: $70 \%$ decrease vs. untreated HUVEC; 4 h: $66 \%$ decrease vs. untreated HUVEC; 5 h: $64 \%$ decrease vs. untreated HUVEC; fig. 4a). Western blots demonstrated that compound 0012 attenuated cyclic strain-induced VEGF protein expression ( $2 \mathrm{~h}$ : $19 \%$ decrease vs. untreated HUVEC; 4 h: 53\% decrease vs. untreated HUVEC; 6 h: 31\% decrease vs. untreated HUVEC; fig. 4b). Thus, by silencing c-Myc expression through the use of compound 0012, the upregulation of VEGF mRNA and protein expression can be attenuated.

\section{Cyclic Strain Increases HSP60 mRNA and Protein \\ Expression in a Time-Dependent Manner}

Exposure of HUVEC to varying time periods of cyclic strain $(1 \mathrm{~Hz}, 20 \%)$ resulted in an increase in HSP60 mRNA and protein expression (fig. 5). Induction of HSP60 peaked at $4 \mathrm{~h}(2.6 \pm 0.7$-fold vs. static), and began declining at 5 and $6 \mathrm{~h}(5 \mathrm{~h}: 2.4 \pm 0.5$-fold vs. static; $6 \mathrm{~h}$ : $2.4 \pm 0.1$-fold vs. static). As seen by Western blot analysis, protein expression peaked at $4 \mathrm{~h}$ of cyclic strain (1.8 \pm 0.1 -fold vs. static).

\section{Compound 0012 Attenuates HSP60 Expression}

Compared with untreated HUVEC, compound 0012 attenuated HSP60 protein expression. Although the effect of compound 0012 is not significant for mRNA expression at early time points, incubation with compound 0012 inhibited HSP60 expression at $4 \mathrm{~h}$ (11\% decrease vs. untreated HUVEC), $5 \mathrm{~h}$ (32\% decrease vs. untreated HUVEC) and $6 \mathrm{~h}$ (45\% decrease vs. untreated HUVEC).

Cyclic strain-induced HSP60 protein expression is significantly inhibited by compound 0012 at $4 \mathrm{~h}(50 \%$ decrease vs. untreated HUVEC). Thus, by silencing c-Myc expression through the use of compound 0012, the cyclic strain-induced expression of HSP60 mRNA and protein can be attenuated.

\section{Discussion}

The principal goal of this study is to offer a possible mechanism which might lead to a promising clinical treatment for vascular diseases initiated by increased cyclic strain. The unifying theory is that higher levels of 
uniaxial cyclic strain (15-20\%) lead to c-Myc transcription and downstream gene induction, which, in sum, contribute to the generation of vascular proliferative diseases. In order to substantiate this hypothesis, this study verifies that induction of c-Myc mRNA and protein expression only occur at elevated levels of cyclic strain (15$20 \%$ ), which is within the range of pathological strain $[6$, 7]. This 2.5 -fold upregulation peaks in the 1.5- to 2-hour range and falls to basal levels by $3 \mathrm{~h}$.

Additionally, since fluid agitation may alter gene expression, our cyclic strain system takes into account the fluid agitation inherent in the strain apparatus, by including a motion control condition. In Sung et al. [21], we found that the motion control response of human aortic endothelial cells was more robust than the response to cyclic strain, as indicated by several indicators of oxidative stress. The devices used in many strain studies do not allow for a motion control; therefore, many of the reported cellular responses to cyclic strain have not been confirmed as actual cyclic strain responses. The inclusion of a motion control condition allows evaluation of whether fluid agitation is important in the regulation of the expression of genes of interest in the study. With any in vitro cyclic strain model, cells are concomitantly exposed to low fluid motion-induced oscillating shear stress and convective transport due to fluid agitation from piston motion $[16,17]$. Previous studies from our laboratory have shown that fluid motion from the motion control condition increased production of ET-1 and prostacyclin, albeit not as much as in strained cells [17]. In more recent work, the motion controls gave similar results to the static controls in studies of PAR-1 gene expression [22]. In the present study, we found that the motion control condition had no significant effect on c-Myc expression (fig. 1a and c).

Recently, Kuo et al. [9] showed that EC survival was increased by $5 \%$ cyclic strain while $20 \%$ cyclic strain decreased EC survival and tubulogenesis. Sadoshima et al. [23] reported that $20 \%$ uniaxial cyclic straining of cardiac myocytes transiently increased c-Myc mRNA at $1 \mathrm{~h}$. Other groups have investigated the effects of shear stress on c-Myc. Hsieh et al. [24] found that 4 and 10 dynes $/ \mathrm{cm}^{2}$ shear stress significantly increased c-Myc protein expression. These levels peaked at $1.5 \mathrm{~h}$ and fell to basal levels by $2.5 \mathrm{~h}$. Similarly, Li et al. [25] demonstrated that $1 \mathrm{~Hz}$ pulsatile flow (average shear stress of 16 dynes $/ \mathrm{cm}^{2}$ ) caused slight increases in c-Myc mRNA levels, which peaked at $2 \mathrm{~h}$ and returned to basal levels by $4 \mathrm{~h}$.

Having provided evidence that pathogenic levels of cyclic strain lead to c-Myc transcription, our subsequent studies were aimed at determining if this induction was due to activation of the c-Myc promoter and, more importantly, if this activation could be modulated. We employed the small-molecule compound 0012, which specifically targets the c-Myc promoter. The success of this compound in attenuating cyclic strain-induced c-Myc mRNA and protein expression (50\% decrease) indicates that c-Myc expression is upregulated, at least in part, through activation of the promoter region of c-Myc.

With the establishment that compound 0012 can reduce c-Myc expression, the possibility of also modulating the downstream genes of c-Myc, particularly those related to vascular disease, was investigated. c-Myc has been identified as playing important roles in vascular disease differential gene expression profiles [26-30]. Although transient, since expression of c-Myc in the normal cell is tightly regulated, this expression change has enormous implications for downstream targets. In fact, c-Myc is referred to as a 'global regulator of transcription' because it controls the expression of about 15\% (3,0004,000 genes) of the genome [31]. These target genes are involved in proliferation, apoptosis, metabolism, migration and remodeling.

Accordingly, pertinent c-Myc target genes were chosen on the basis of their roles in these initiation events. The selected genes, VEGF, HSP60 and PCNA, are 3 markers often monitored for initiation and progression of vascular pathologies [32-41]. PCNA is identified as playing an important role in vascular remodeling (proliferation, migration and phenotypic change). The expression of PCNA is frequently used to determine the proliferation activity of endothelial cells in restenotic tissue [42] and matrix accumulation in neointimal vasculature [34] obtained from porcine coronary angioplasty. HSP60 is recognized as a marker for early cardiovascular disease because elevated levels have been identified in patients with borderline hypertension and early atherosclerosis [37]. Lastly, VEGF, although necessary for maintaining hemostasis, is essential to the development of restenosis found in atherosclerotic and restenotic lesions compared with normal healthy tissue $[43,44]$.

Although each gene can be isolated to determine its individual role in proliferative vascular disease, it may be their concerted effects that result in decreased vessel lumen size. Together, these genes are key players in the vasculoproliferative cascade, beginning with regulation of the cell cycle and the inflammatory response, and culminating with vascular remodeling. Examination of the reported mRNA and protein expression profile of each gene presents the opportunity to propose a potential 
timeline governing this proliferative process. From our results, it is reasonable to postulate that upregulation of c-Myc triggers the expression of PCNA and VEGF, followed by HSP60. These time points can be further substantiated by extrapolating to the known progression of events in vivo.

Animal studies suggest that vascular cell proliferation is the prevailing event in the initiation of vascular diseases [45]. Not only are PCNA, VEGF and HSP60 intimately linked to regulating the cell cycle, each gene mediates its effects at a different phase. Thus, their concerted expression allows direct cell cycle regulation at the G1, S and G2 phases. VEGF can directly stimulate cell cycle progression from the $\mathrm{G} 1$ to the $\mathrm{S}$ phase [46] and can mediate indirect effects through cell cycle regulators p27 and p130 [47]. PCNA is essential for the $S$ phase of the cell cycle. Last, heat shock proteins protect cells from apoptosis and reverse cell arrest in the G2 phase [48]. Upon intimal injury, there is early cell proliferation, which is likely mediated by the expression of HSP60 and PCNA. Next, arterial remodeling begins at the injury site, which, similar to the reported expression of VEGF, is sustained. In addition, the implicated roles of VEGF, such as wound healing, neovascularization and endothelial cell migration [40], are pivotal to vascular remodeling. Hence, these parallels corroborate the argument that remodeling is at least partly accomplished through the activation of VEGF.

Our findings indicate that the upregulation of c-Myc by cyclic strain leads to expression of these $3 \mathrm{c}$-Myc downstream genes. By employing compound 0012 to silence the c-Myc promoter, we are able to prevent, to varying degrees, the expression of PCNA, VEGF and HSP60. It should be noted that other c-Myc downstream genes, such as matrix metalloproteinase- 9 and cyclin-dependent kinase 4, implicated in the progression of vascular proliferative disease, warrant future studies.

A promising contribution of this research is the identification of a possible novel treatment for vascular disease. Restenosis after surgical intervention is a major clinical problem, occurring in $30-50 \%$ of patients [49, 50]. Anticoagulants, anti-inflammatory and anti-proliferative drugs have been unsuccessful at preventing restenosis [39]. Since restenosis after stent placement often results in intimal hyperplasia, stent coatings with drugs or nonpharmaceutical agents may reduce in-stent restenosis. However, since the currently employed drugs fail to specifically target the factors involved in the vascular injury caused by surgical implantation, there are complications known as 'late stent thrombosis'. The antiprolifera- tive agents prevent the growth of endothelial cells onto the stent, thereby increasing the tendency for blood clotting on the stent. This complication is generally avoided in bare metal stents because they promote the growth of a smooth thin layer of endothelial cells, incorporating the device into the artery.

A possible solution could be a drug-eluting stent that employs a novel small molecule compound, such as compound 0012 , which acts at the transcriptional control level to specifically modulate the factors involved in vascular injury. Drugs that target transcriptional factors instead of signaling molecules, which are upstream of signaling cascades, are advantageous because there is less likely to be redundancy due to upregulation of parallel pathways, resulting in drug resistance. On the basis of these ideal drug characteristics and the data reported here, compound 0012 is an excellent candidate for the treatment of in-stent restenosis.

Results demonstrate the effectiveness of compound 0012 in not only reducing c-Myc protein expression by more than $50 \%$, but also in decreasing the expression of downstream genes (VEGF, HSP60 and PCNA) that contribute to vascular remodeling pathologies. It can be postulated, on the basis of the roles of these genes, that compound 0012 inhibits key targets in the cell cycle, while also potentially preventing inflammation and vascular remodeling.

In summary, our results indicate that pathological levels of cyclic strain upregulate the transcription factor cMyc. This event can be effectively modulated by using a compound that prevents c-Myc transcription at the promoter region. More importantly, the expression of downstream genes of c-Myc, which contribute to vascular remodeling, can also be attenuated. These findings may help in the development of a novel therapeutic opportunity in vascular diseases.

\section{Acknowledgments}

This work is supported by grants from the National Institutes of Health (HL-18762 and CA-95060). Tiffanie Bialis provided valuable experimental and technical assistance. 


\section{References}

1 Kakisis JD, Liapis CD, Sumpio BE: Effects of cyclic strain on vascular cells. Endothelium 2004;11:17-28.

2 Thubrikar MJ, Robicsek F: Pressure-induced arterial wall stress and atherosclerosis. Ann Thorac Surg 1995;59:1594-1603.

-3 Dobrin PB: Mechanical properties of arteries. Physiol Rev 1978;58:397-460.

4 O’Rourke M: Mechanical principles in arterial disease. Hypertension 1995;26:2-9.

5 Goldsmith HL, Turitto VT: Rheological aspects of thrombosis and haemostasis: basic principles and applications. ICTH-Report Subcommittee on Rheology of the International Committee on Thrombosis and Haemostasis. Thromb Haemost 1986;55:415435.

-6 Liu XM, Ensenat D, Wang H, Schafer AI, Durante $\mathrm{W}$ : Physiologic cyclic stretch inhibits apoptosis in vascular endothelium. FEBS Lett 2003;541:52-56.

7 Haga JH, Li YS, Chien S: Molecular basis of the effects of mechanical stretch on vascular smooth muscle cells. J Biomech 2007;40: 947-960.

-8 Birukov KG, Jacobson JR, Flores AA, Shui Q, Birukova AA, Verin AD, Garcia JGN: Magnitude-dependent regulation of pulmonary endothelial cell barrier function by cyclic stretch. Am J Physiol 2003;285:L785-L797.

$\checkmark 9$ Kou B, Zhang J, Singer DRJ: Effects of cyclic strain on endothelial cell apoptosis and tubulogenesis are dependent on ROS production via $\mathrm{NAD}(\mathrm{P}) \mathrm{H}$ subunit $\mathrm{p} 22$ phox. Microvasc Res 2009;77:125-133.

$\checkmark 10$ Lehoux S, Castier Y, Tedgui A: Molecular mechanisms of the vascular responses to haemodynamic forces. J Int Med 2006;259: 381-392.

-11 Hurley LH, Von Hoff DD, Siddiqui-Jain A, Yang D: Drug targeting of the c-MYC promoter to repress gene expression via a Gquadruplex silencer element. Semin Oncol 2006;33:498-512.

12 de Nigris F, Sica V, Herrmann J, Condorelli G, Chade AR, Tajana G, Lerman A, Lerman LO, Napoli C: C-myc oncoprotein: cell cyclerelated events and new therapeutic challenges in cancer and cardiovascular diseases. Cell Cycle 2003;2:325-328.

-13 Seenisamy J, Rezler EM, Powell TJ, Tye D, Gokhale V, Joshi CS, Siddiqui-Jain A, Hurley LH: The dynamic character of the G-quadruplex element in the c-MYC promoter and modification by TMPyP4. J Am Chem Soc 2004; 126:8702-8709.

14 Siddiqui-Jain A, Grand CL, Bearss DJ, Hurley LH: Direct evidence for a G-quadruplex in a promoter region and its targeting with a small molecule to repress c-MYC transcription. Proc Natl Acad Sci USA 2002;99:1159311598.
15 Smeets EF, von Asmuth EJ, van der Linden CJ, Leeuwenberg JF, Buurman WA: A comparison of substrates for human umbilical vein endothelial cell culture. Biotech Histochem 1992;67:241-250.

-16 Frye SR, Yee A, Eskin SG, Guerra R, Cong X, McIntire LV: cDNA microarray analysis of endothelial cells subjected to cyclic mechanical strain: importance of motion control. Physiol Genomics 2005;21:124-130.

17 Carosi JA, Eskin SG, McIntire LV: Cyclical strain effects on production of vasoactive materials in cultured endothelial cells. J Cell Physiol 1992;151:29-36.

18 Marcu KB, Patel AJ, Yang Y: Differential regulation of the c-MYC $\mathrm{p} 1$ and $\mathrm{p} 2$ promoters in the absence of functional tumor suppressors: implications for mechanisms of deregulated MYC transcription. Curr Top Microbiol Immunol 1997;224:47-56.

-19 Simonsson T, Pecinka P, Kubista M: DNA tetraplex formation in the control region of c-MYC. Nucleic Acids Res 1998;26:11671172 .

20 Weinstein IB: Cancer: addiction to oncogenes - the achilles heal of cancer. Science 2002;297:63-64.

21 Sung H, Yee A, Eskin SG, McIntire LV: Cyclic strain and motion control produce opposite oxidative responses in two human endothelial cell types. Am J Physiol Cell Physiol 2007; 293:C87-C94.

-22 Nguyen KT, Frye SR, Eskin SG, Patterson C, Runge MS, McIntire LV: Cyclic strain increases protease-activated receptor-1 expression in vascular smooth muscle cells. Hypertension 2001;38:1038-1043.

23 Sadoshima J, Jahn L, Takahashi T, Kulik TJ, Izumo S: Molecular characterization of the stretch-induced adaptation of cultured cardiac cells. An in vitro model of load-induced cardiac hypertrophy. J Biol Chem 1992;267: 10551-10560.

24 Hsieh HJ, Li NQ, Frangos JA: Pulsatile and steady flow induces c-fos expression in human endothelial cells. J Cell Physiol 1993; 154:143-151.

25 Li C, Zeng Y, Hu J, Yu H: Effects of fluid shear stress on expression of proto-oncogenes cfos and c-myc in cultured human umbilical vein endothelial cells. Clin Hemorheol Microcirc 2002;26:117-123.

-26 De Feo M, Forte A, Onorati F, Renzulli A, Cipollaro M, Cotrufo M, Rossi F, Cascino A: Rat carotid arteriotomy: c-myc is involved in negative remodelling and apoptosis. J Cardiovasc Med (Hagerstown) 2006;7:61-67.

27 Komuro I, Kurihara H, Sugiyama T, Yoshizumi M, Takaku F, Yazaki Y: Endothelin stimulates c-fos and c-myc expression and proliferation of vascular smooth muscle cells. FEBS Lett 1988;238:249-252.
-28 Naftilan AJ, Pratt RE, Eldridge CS, Lin HL, Dzau VJ: Angiotensin II induces c-fos expression in smooth muscle via transcriptional control. Hypertension 1989;13:706-711.

-29 Kipshidze N, Tsapenko M, Iversen P, Burger D: Antisense therapy for restenosis following percutaneous coronary intervention. Expert Opin Biol Ther 2005;5:79-89.

30 von Rahden BH, Stein HJ, Puhringer-Oppermann F, Sarbia M: c-myc amplification is frequent in esophageal adenocarcinoma and correlated with the upregulation of VEGF-A expression. Neoplasia 2006;8:702-707.

>31 Dang CV, O’Donnell KA, Zeller KI, Nguyen T, Osthus RC, Li F: The c-myc target gene network. Semin Cancer Biol 2006;16:253264.

$>32$ de Graaf R, Kloppenburg G, Kitslaar PJ, Bruggeman CA, Stassen F: Human heat shock protein 60 stimulates vascular smooth muscle cell proliferation through Toll-like receptors 2 and 4. Microbes Infect 2006;8: 1859-1865.

>33 Yoshio Y, Miyazaki M, Abe K, Nishino T, Furusu A, Mizuta Y, Harada T, Ozono Y, Koji T, Kohno S: TNP-470, an angiogenesis inhibitor, suppresses the progression of peritoneal fibrosis in mouse experimental model. Kidney Int 2004;66:1677-1685.

34 Malik N, Francis SE, Holt CM, Gunn J, Thomas GL, Shepherd L, Chamberlain J, Newman CM, Cumberland DC, Crossman DC: Apoptosis and cell proliferation after porcine coronary angioplasty. Circulation 1998;98:1657-1665.

>35 Xu Q, Schett G, Perschinka H, Mayr M, Egger G, Oberhollenzer F, Willeit J, Kiechl S, Wick G: Serum soluble heat shock protein 60 is elevated in subjects with atherosclerosis in a general population. Circulation 2000;102: 14-20.

36 Chen SJ, Li H, Durand J, Oparil S, Chen YF: Estrogen reduces myointimal proliferation after balloon injury of rat carotid artery. Circulation 1996;93:577-584.

37 Pockley AG, Wu R, Lemne C, Kiessling R, de Faire U, Frostegard J: Circulating heat shock protein 60 is associated with early cardiovascular disease. Hypertension 2000;36:303307.

$\checkmark 38$ Kol A, Bourcier T, Lichtman AH, Libby P: Chlamydial and human heat shock protein 60 s activate human vascular endothelium, smooth muscle cells, and macrophages. J Clin Invest 1999;103:571-577.

>39 Farb A, John M, Acampado E, Kolodgie FD, Prescott MF, Virmani R: Oral everolimus inhibits in-stent neointimal growth. Circulation 2002;106:2379-2384.

40 Rutanen J, Puhakka H, Yla-Herttuala S: Post-intervention vessel remodeling. Gene Ther 2002;9:1487-1491. 
-41 Gruchala M, Roy H, Bhardwaj S, Yla-Herttuala S: Gene therapy for cardiovascular diseases. Curr Pharm Des 2004;10:407-423.

-42 Taylor AJ, Farb AA, Angello DA, Burwell LR, Virmani R: Proliferative activity in coronary atherectomy tissue. Clinical, histopathologic, and immunohistochemical correlates. Chest 1995; 108:815-820.

43 Inoue M, Itoh H, Ueda M, Naruko T, Kojima A, Komatsu R, Doi K, Ogawa Y, Tamura N, Takaya K, Igaki T, Yamashita J, Chun TH, Masatsugu K, Becker AE, Nakao K: Vascular endothelial growth factor (VEGF) expression in human coronary atherosclerotic lesions: possible pathophysiological significance of VEGF in progression of atherosclerosis. Circulation 1998;98:2108-2116.
44 Shibata M, Suzuki H, Nakatani M, Koba S, Geshi E, Katagiri T, Takeyama Y: The involvement of vascular endothelial growth factor and flt- 1 in the process of neointimal proliferation in pig coronary arteries following stent implantation. Histochem Cell Biol 2001;116:471-481.

45 Andres V, Castro C: Antiproliferative strategies for the treatment of vascular proliferative disease. Curr Vasc Pharmacol 2003;1: 85-98.

46 Woo SH, Park MJ, An S, Lee HC, Jin HO, Lee SJ, Gwak HS, Park IC, Hong SI, Rhee CH: Diarsenic and tetraarsenic oxide inhibit cell cycle progression and BFGF- and VEGF-induced proliferation of human endothelial cells. J Cell Biochem 2005;95:120-130.

47 Sutherland S: Cell cycle inhibitors key to neoangiogenesis. Drug Discov Today 2005; 10:1015-1016.
48 Martinez-Diez M, Santamaria G, Ortega $\mathrm{AD}$, Cuezva JM: Biogenesis and dynamics of mitochondria during the cell cycle: significance of 3'UTRs. PLoS ONE 2006;1:e107.

49 Fischman DL, Leon MB, Baim DS, Schatz RA, Savage MP, Penn I, Detre K, Veltri L, Ricci D, Nobuyoshi M, et al: A randomized comparison of coronary-stent placement and balloon angioplasty in the treatment of coronary artery disease. Stent restenosis study investigators. N Engl J Med 1994;331: 496-501.

50 Serruys PW, de Jaegere P, Kiemeneij F, Macaya C, Rutsch W, Heyndrickx G, Emanuelsson H, Marco J, Legrand V, Materne P, et al: A comparison of balloon-expandable-stent implantation with balloon angioplasty in patients with coronary artery disease. Benestent study group. N Engl J Med 1994;331: 489-495. 